\title{
Variation of Glucosinolate Composition during Seedling and Growth Stages of Brassica rapa L. ssp. pekinensis
}

\author{
Eunyoung Hong and Gun-Hee Kim* \\ Department of Food and Nutrition, Duksung Women's University, Seoul 132-714, Korea
}

\begin{abstract}
The objective of this study was to evaluate glucosinolate (GSL) profiles and variation of total and individual GSLs concentrations within seedling (0-14 days) and growth stages (0-15 weeks) of Korean Chinese cabbage (Brassica rapa L. ssp. pekinensis). Ten GSLs (progoitrin, glucoraphanin, glucoalyssin, gluconapin, glucobrassicanapin, 4-hydroxyglucobrassin, glucobrassicin, 4-methoxyglucobrassicin, neoglucobrassicin and gluconasturtiin) were identified from Korean Chinese cabbage. In general, total GSL content significantly decreased during seedling (from 92.89 to $35.26 \mu \mathrm{mol} \cdot \mathrm{g}^{-1} \mathrm{DW}$ ) and growth stages (from 74.11 to 1.97 $\left.\mu \mathrm{mol} \cdot \mathrm{g}^{-1} \mathrm{DW}\right)$. Gluconapin was the highest in seeds and in the germination period $\left(73.1 \mu \mathrm{mol} \cdot \mathrm{g}^{-1} \mathrm{DW}\right)$ and declined gradually from 73 to $15 \%$ during seedling stages. The level of the major aliphatic GSLs, gluconapin and progoitrin, tended to decrease sharply, whereas levels of indolic GSLs (4-methoxyglucobrassicin, glucobrassicin) and aromatic GSLs (gluconasturtiin) were found to increase generally at the beginning of growth stages.
\end{abstract}

Additional key words: Chinese cabbage, principal component analysis

\section{Introduction}

Brassica vegetables belong to Cruciferous family and include many varieties of cabbage (Chinese, savoy, swamp, red and white), cauliflower, broccoli, Brussels sprouts and kale, which are consumed in high quantities all over the world (Podsedek, 2007). These vegetables possess both antioxidant and anti-carcinogenic properties (Chu et al., 2002; Cohen et al., 2000; Verhoeven et al., 1997). Especially, Chinese cabbage (Brassica rapa L. ssp. pekinensis) is extensively used in Asia and the major ingredient in Kimchi, a representative Korean salted and fermented vegetable. Kimchi has an important role in the diet and nutrition of Koreans (Lee, 1997) and has become popular throughout the world. Most studies on bioactive compounds in Brassica vegetables have focused on the content of glucosinolates (GSLs), a nitrogen and sulphur-containing group of compounds that is especially abundant in these species.

GSLs are $\beta$-thioglucoside $N$-hydroxysulfates containing a side chain and a $\beta$-d-glucopyranosyl moiety (Mithen et al., 2000). The highly variable structure of the side chain includes aliphatic (i.e. straight chain, branched chain, hydroxylated, sulfur containing, keto-derivatives), alkenylic, aromatic, hydroxyalkyl benzoated or indolic moieties and can be multiply glycosylated. Aliphatic GSLs are derived from methionine, aromatic GSLs from phenylalanine (and possibly tyrosine), and indoly GSLs from tryptophan (Fahey et al., 2001). Upon disruption of plant tissues, GSLs are hydrolyzed to various bioactive degradation products by the endogenous enzyme myrosinase (thioglucohydrolase; E.C. 3.2.1.1). These degradation products include isothiocyanates, nitriles, thiocyanates and other minor products (Fenwick et al., 1983a, 1983b) depending on the substrate, $\mathrm{pH}$ conditions, availability of ferrous ions, and the level and activity of specific protein factors such as the epithiospecifier protein (ESP) (Halkier and Du, 1997). GSLs, myrosinase and degradation products constitute a frequently-studied plant defense system that appears to deter generalist herbivores and pathogens (Chew,

\footnotetext{
*Comesponding author: ghkim@duksung.ac.kr

※ Received 10 March 2014; Revised 1 May 2014; Accepted 8 June 2014. This work was supported by Priority Research Centers Program through the National Research Foundation of Korea (NRF) funded by the Ministry of Education, Science and Technology (2009-0094017).

(C) 2014 Korean Society for Horticultural Science
} 
1988; Renwick, 2001). GSLs and their breakdown products are known to have important several biological activities including anti-carcinogenic, anti-fungal and anti-bacterial effects (Fenwick et al., 1983a, 1983b).

Variation of GSL composition and concentration in Brassica vegetables is caused by many factors: varieties, different plant organs and development stages, growing and environmental conditions, post-harvest storage and handling procedures (Jeffery et al., 2003; Vallejo et al., 2002). The concentration of potentially health beneficial GSLs for a given species has been found to be greater in seed sprout vegetables are scarce and much of the literature still focuses upon either fully grown plants of $B$. oleracea crops (Charron et al., 2005; Ciska et al., 2000; Kushad et al., 1999) or seeds (Mattaus and Luftmann, 2000; West et al., 2004). De March et al. (1989) examined the variation of GSLs content during pod and seed maturity. However, the composition of individual GSLs has not been studied in detail during plant growth and development. Especially, a comprehensive understanding of the GSL profiles and contents during seeding and leaf development of Korean Chinese cabbage is still lacking.

The proportion of each individual GSL contributing to the concentration may significantly alter the biological effects of the crop at various growth stages. Variation of individual and total GSL contents represents the net effect of biosynthesis, transport and catabolism of GSLs, and precise knowledge of the GSL profiles in various growth stages provides a foundation for studying the relative importance of these physiological processes. Therefore, the objective of this study was to investigate changes of individual GSL concentration during plant development from sowing to harvest in Korean Chinese cabbage.

\section{Materials and Methods}

\section{Young Seedlings in the Laboratory}

Seeds of 'Winter pride' cultivar of Korean Chinese cabbage were obtained from Seminis Korea Co. (Seoul, Republic of Korea). In the laboratory, seeds were soaked in distilled water at room temperature $\left(25 \pm 2^{\circ} \mathrm{C}\right)$ for $6 \mathrm{~h}$. The distilled water was drained off, and then the soaked seeds were placed on moist cotton gauze in sprouting equipment $(26$ $\times 17 \times 16 \mathrm{~cm}$, Miraewon Agricultural Co., Ltd., Gyeonggi-do, Republic of Korea) for germination and sprouts. The seeds were germinated in dark at $25^{\circ} \mathrm{C}$, for up to 2 days. They were then grown with a $16 \mathrm{~h}$ light and $8 \mathrm{~h}$ dark photoperiod and a corresponding $25 / 20^{\circ} \mathrm{C}$ cycle for grown sprouts. To maintain moistness, a small quantity of water was added to the sprouting equipment regularly. Grown sprouts during from 0 to 14 days were taken out every $24 \mathrm{~h}$, and lyophilized. All experiments were conducted in triplicate.

\section{Cultivation in the Greenhouse}

Seeds ('Winter pride' cultivar) were planted by direct seeding method in the greenhouse (Duksung Women's University, Seoul, Republic of Korea). Korean Chinese cabbage was grown during a period from 0 to 15 weeks at an average temperature of $20-25^{\circ} \mathrm{C}, 60-80 \%$ relative humidity and used natural fertilizers. Water supply and insect and disease controls were properly done. Korean Chinese cabbage of each grown stages were harvested once every week after being sown, immediately freeze dried and stored at $-70^{\circ} \mathrm{C}$.

\section{Chemical Reagents}

Sinigrin monohydrate from horseradish (99\%) and Helix pomatia type $\mathrm{H}-1$ sulphatase (EC 3.1.6.1) were purchased from Sigma-Aldrich (St. Louis, MO, USA). Diethylaminoethyl (DEAE)-Sephadex A25 was obtained by GE Healthcare (Uppsala, Sweden). Ethanol and acetonitrile (ACN) were of high-pressure liquid chromatography (HPLC) grade, and ultrapure water was produced using a Milli-Q RG system from Millipore (Bedford, MA, USA).

\section{Extraction and Desulfation of Glucosinolates}

Desulfo-GSLs were determined according to a modified method described by ISO 9167-1 (ISO 9167, 1992). In brief, $50 \mathrm{mg}$ freeze-dried samples were extracted with $1.5 \mathrm{~mL}$ boiling $70 \%(\mathrm{v} / \mathrm{v})$ ethanol in a water bath at $70^{\circ} \mathrm{C}$ for $5 \mathrm{~min}$. And then, centrifugation $\left(13,000 \times \mathrm{g}\right.$ at $4^{\circ} \mathrm{C}$ for 20 $\mathrm{min}$ ), the supernatant was collected in a $10 \mathrm{~mL}$ test tube. The residue was extracted twice using the same procedure. Desulfation of the GSLs was performed on DEAE anion exchange columns. The columns were prepared by adding a slurry of Sephadex A25 (about $40 \mathrm{mg}$ DW) activated with $0.5 \mathrm{M}$ sodium acetate to a mini-column using a 1.0 $\mathrm{mL}$ pipette tip. Also, GSLs were desulfated by adding a solution of aryl sulfatase (75 $\mu \mathrm{L}, 28.7$ units) to the column. After overnight reaction at ambient temperature, DesulfoGSLs were eluted with $1.0 \mathrm{~mL}$ deionized water $0.5 \mathrm{~mL}$ $\times 2$ ) and filtered through a $0.45 \mu \mathrm{m}$ Teflon PTEE syringe filter for analysis. The elutes were analyzed immediately by HPLC or at $-20^{\circ} \mathrm{C}$ until chemical analysis.

\section{Determination of Desulfo-glucosinolates by HPLC Analysis}

For quantitative analysis, desulfo-GSLs were separated 
by HPLC (Dionex, Sunnyvale, CA, USA) on an Inertsil ODS2 (C18) column (4.6 × $250 \mathrm{~mm}$; GS Science, Tokyo, Japan). The column oven temperature was set to $35^{\circ} \mathrm{C}$ and a flow rate of $1.0 \mathrm{~mL} \cdot \mathrm{min}^{-1}$. The wavelength was set at $227 \mathrm{~nm}$ using a variable wavelength detector. The solvent system employed was (A) deionized water and (B) $20 \%(\mathrm{v} / \mathrm{v}$ ) acetonitrile. The samples were separated according to the following gradient: a linear gradient of $1 \%$ to $99 \%$ solvent B for $18 \mathrm{~min}, 99 \%$ solvent B for the next $11 \mathrm{~min}$, and a linear step from $99 \%$ to $1 \%$ solvent B for 3 min. HPLC profiles were obtained by injecting samples of a known volume $(20 \mu \mathrm{L})$. Separated individual GSL peaks were characterized using liquid chromatography-electrospray ionization-mass spectrometry (LC-ESI-MS) analysis. DesulfoGSL contents were calculated using sinigrin as an external standard and obtained by summing the individual GSLs identified.

\section{LC/MS Analysis of Desulfo-glucosinolates}

For identification of desulfo-GSLs, the column eluate was split, and $0.2 \mathrm{~mL} \cdot \mathrm{min}^{-1}$ directed to a Finnigan LCQ Advantage IT mass spectrometer (Thermo-Quest; Thermo Finnigan, San Jose, CA, USA) equipped with an ESI interface after passing through the flow cell of the photodiode array detector. Analysis was conducted using positive electrospray ionization source at a capillary temperature of $250^{\circ} \mathrm{C}$, spray voltage of $5.5 \mathrm{kV}$, capillary voltage of $2.3 \mathrm{~V}$, and tube lens offset of $48 \mathrm{~V}$. Spectral data were recorded with $\mathrm{N}_{2}$ as collision gas (sheath gas of 28 arbitrary units). Data were collected and processed using the Xcalibur 1.4 version software program (Thermo Electron, Waltham, MA, USA).

\section{Principal Component Analysis (PCA)}

Variation of GSL composition during seedlings and growth stages of Korean Chinese cabbage were exported to an Excel spreadsheet and analyzed using principal component analysis (PCA). PCA is multivariate modeling method where the information in the original variables is projected onto a small number of underlying variables called principal components. Plotting the principal components can reveal interrelationships between the variables (loading plot) and detect sample patterns, grouping, similarities or differences (score plot). The PCA was performed using the SAS 9.1 software package (SAS Institute, Cary, NC). All data were visualized as a two-dimensional (two PCs) scatter plot using the principal components score and loading plots.

\section{Results and Discussion}

In this study, ten different individual GSLs, namely progoitrin (peak no. 1, $7.23 \mathrm{~min}$ ), glucoraphanin (no. 2, 7.59 min), glucoalyssin (no. 3, $9.41 \mathrm{~min}$ ), gluconapin (no. 4, $11.86 \mathrm{~min}$ ), 4-hydroxyglucobrassin (no. 5, $12.88 \mathrm{~min}$ ), glucobrassicanapin (no. 6, $16.03 \mathrm{~min}$ ), glucobrassicin (no. 7, $18.19 \mathrm{~min}$ ), 4-methoxyglucobrassicin (no. 8, $20.50 \mathrm{~min}$ ), neoglucobrassicin (no. 9, $22.34 \mathrm{~min}$ ) and gluconasturtiin

Table 1. ESI-MS spectra for desulfo-glucosinolates identified in Korean Chinese cabbage during seedling and growth stages.

\begin{tabular}{|c|c|c|c|c|c|c|c|}
\hline No. $^{z}$ & $\mathrm{RT}^{\mathrm{y}}$ & $\begin{array}{l}\text { Structures of } \\
\text { R-group }\end{array}$ & $\begin{array}{l}\text { Semisystematic names } \\
\text { of R-group }^{\mathrm{x}}\end{array}$ & Travial names & $\operatorname{MS}(m / z)$ & Abbreviation & $\begin{array}{l}\text { Response } \\
\text { factors }^{w}\end{array}$ \\
\hline 1 & 7.23 & $\mathrm{CH}_{2}=\mathrm{CHCH}(\mathrm{OH}) \mathrm{CH}_{2^{-}}$ & 2-Hydroxy-3-butenyl & Progoitrin & $309.65[\mathrm{M}+\mathrm{H}]^{+}, 618.88[2 \mathrm{M}+\mathrm{H}]^{+}$ & PRO & 1.09 \\
\hline 2 & 7.59 & $\mathrm{CH}_{3}-\mathrm{SO}-\left(\mathrm{CH}_{2}\right)_{4}^{-}$ & 4-Methylsulphinylbutyl & Glucoraphanin & $357.63[\mathrm{M}+\mathrm{H}]^{+}, 714.51[2 \mathrm{M}+\mathrm{H}]{ }^{+}$ & GRA & 1.07 \\
\hline$(-)$ & 8.29 & $\mathrm{CH}_{2}=\mathrm{CHCH}_{2-}$ & 2-Propenyl & Sinigrin $^{v}$ & $558.83[2 \mathrm{M}+\mathrm{H}]{ }^{+}$ & SIN & 1.00 \\
\hline 3 & 9.41 & $\mathrm{CH}_{3} \mathrm{SO}\left(\mathrm{CH}_{2}\right)_{5^{-}}$ & 5-Methylsulfinnylpentyl & Glucoalyssin & $371.66[\mathrm{M}+\mathrm{H}]^{+}, 742.47[2 \mathrm{M}+\mathrm{H}]{ }^{+}$ & GAL & 1.07 \\
\hline 4 & 11.86 & $\mathrm{CH}_{2}=\mathrm{CH}-(\mathrm{CH} 2)_{2}-$ & 3-Butenyl & Gluconapin & $293.55[\mathrm{M}+\mathrm{H}]{ }^{+}, 586.21[2 \mathrm{M}+\mathrm{H}]{ }^{+}$ & GNA & 1.11 \\
\hline 5 & 12.88 & Indole $(\mathrm{OH})-3-\mathrm{CH}_{2}-$ & 4-Hydroxy-3-indolylmethyl & 4-Hydroxyglucobrassin & $384.67[\mathrm{M}+\mathrm{H}]^{+}, 768.54[2 \mathrm{M}+\mathrm{H}]{ }^{+}$ & 4-OHGBS & 0.28 \\
\hline 6 & 16.03 & $\mathrm{CH}_{2}=\mathrm{CH}-\left(\mathrm{CH}_{2}\right)_{3}-$ & 4-Pentenyl & Glucobrassicanapin & $307.99[\mathrm{M}+\mathrm{H}]]^{+}, 614.46[2 \mathrm{M}+\mathrm{H}]^{+}$, & GBN & 1.15 \\
\hline 7 & 18.19 & Indole-3- $\mathrm{CH}_{2}-$ & 3-Indolymethyl & Glucobrassicin & $368.94[\mathrm{M}+\mathrm{H}]^{+}, 736.54[2 \mathrm{M}+\mathrm{H}]{ }^{+}$ & GBS & 0.29 \\
\hline 8 & 20.50 & Indole-4- $\mathrm{OCH}_{3}-$ & 4-Methoxy-3-indolymethyl & 4-Methoxyglucobrassicin & $398.99[\mathrm{M}+\mathrm{H}]^{+}$ & 4-OMGBS & 0.25 \\
\hline 9 & 22.34 & $\mathrm{C}_{6} \mathrm{H}_{5}-\left(\mathrm{CH}_{2}\right)_{2-}$ & 2-Phenethyl & Gluconasturtiin & $343.99[\mathrm{M}+\mathrm{H}]{ }^{+}$ & GST & 0.95 \\
\hline 10 & 26.41 & Indole-1-OCH3- & 1-Methoxy-3-indolymethyl & Neoglucobrassicin & 399. $[\mathrm{M}+\mathrm{H}]{ }^{+}, 796.54[2 \mathrm{M}+\mathrm{H}]{ }^{+}$ & NGBS & 0.20 \\
\hline
\end{tabular}

${ }^{\mathrm{z}}$ Number is the elution order of DS-GSL from HPLC chromatograms.

${ }^{\mathrm{y}}$ Retention time (min).

${ }^{\mathrm{x}}$ The semisystematic names of glucosinolates include the name of the R-group followed by the suffix-glucosinolate, e.g., 2-hydroxy-3-butenyl glucosinolate for number 1.

${ }^{{ }^{w}}$ The international organization for standardization (ISO, 1992).

${ }^{\mathrm{v}}$ External standard. 
(no. 10, $26.41 \mathrm{~min}$ ), were detected in plant organs during seedlings and growth stages of Korean Chinese cabbage by LC/MS analysis (Table 1). Especially, gluconasturtiin was first observed in the vegetative tissues in three weeks after sowing. The molecular ion and fragmentation patterns are consistent with literature data (Barbieri et al., 2008) and allowed for unequivocal identification. Ten kinds of GSLs, including five aliphatic, four indolic and one aromatic GSLs based on the structure of different amino acid precursors were detected in sprouts and developed vegetative tissues

Table 2. Composition and content $\left(\mu \mathrm{mol} \cdot \mathrm{g}^{-1} \mathrm{DW}\right)$ of desulfo-glucosinolates during seedling stages $(0-14$ days $)$ of Brassica rapa L. ssp. Peckinensis.

\begin{tabular}{|c|c|c|c|c|c|c|c|c|c|c|c|c|}
\hline \multirow{2}{*}{ Day } & \multicolumn{6}{|c|}{ Aliphatic GSLs } & \multicolumn{5}{|c|}{ Indolic GSLs } & \multirow{2}{*}{ Total GSLs } \\
\hline & PRO & GRA & GAL & GNA & GBN & Sum & 4-OHGBS & GBS & 4-OMGBS & NGBS & Sum & \\
\hline D0 & $4.14 \pm 0.06$ & $2.38 \pm 0.14$ & $2.18 \pm 0.02$ & $53.91 \pm 1.59$ & $3.96 \pm 0.06$ & $66.56 \pm 0.68$ & $7.09 \pm 0.33$ & $0.46 \pm 0.10$ & ND & ND & $7.55 \pm 0.17$ & $74.11 \pm 1.49$ \\
\hline D1 & $7.47 \pm 0.34$ & $2.66 \pm 0.03$ & $2.79 \pm 0.06$ & $68.09 \pm 1.34$ & $5.37 \pm 0.05$ & $86.39 \pm 0.56$ & $5.84 \pm 0.12$ & $0.48 \pm 0.02$ & ND & ND & $6.32 \pm 0.07$ & $92.71 \pm 1.69$ \\
\hline D2 & $10.47 \pm 0.77$ & $1.17 \pm 0.21$ & $2.06 \pm 0.06$ & $56.60 \pm 2.90$ & $5.20 \pm 0.36$ & $75.50 \pm 1.17$ & $5.19 \pm 0.37$ & $0.90 \pm 0.06$ & $0.69 \pm 0.04$ & $0.72 \pm 0.07$ & $7.49 \pm 0.16$ & $82.98 \pm 3.33$ \\
\hline D3 & $15.68 \pm 0.42$ & ND & $1.40 \pm 0.04$ & $50.85 \pm 0.31$ & $5.31 \pm 0.38$ & $73.24 \pm 0.17$ & $4.87 \pm 0.33$ & $1.30 \pm 0.06$ & $2.87 \pm 0.08$ & $1.45 \pm 0.16$ & $10.48 \pm 0.13$ & $83.73 \pm 0.42$ \\
\hline D4 & $24.26 \pm 0.64$ & ND & $1.32 \pm 0.11$ & $49.22 \pm 1.90$ & $5.38 \pm 0.33$ & $80.18 \pm 0.80$ & $2.30 \pm 0.25$ & $1.63 \pm 0.06$ & $6.01 \pm 0.64$ & $2.78 \pm 0.20$ & $12.71 \pm 0.25$ & $92.89 \pm 2.24$ \\
\hline D7 & $26.05 \pm 1.79$ & ND & $0.81 \pm 0.11$ & $40.83 \pm 1.12$ & $5.20 \pm 0.35$ & $72.90 \pm 0.76$ & $1.00 \pm 0.03$ & $1.51 \pm 0.06$ & $8.44 \pm 0.11$ & $5.19 \pm 0.20$ & $16.13 \pm 0.08$ & $89.03 \pm 2.82$ \\
\hline D8 & $26.16 \pm 1.92$ & ND & $0.60 \pm 0.07$ & $28.21 \pm 1.84$ & $0.39 \pm 0.14$ & $59.47 \pm 0.96$ & $0.39 \pm 0.14$ & $1.51 \pm 0.13$ & $9.29 \pm 0.51$ & $5.09 \pm 0.16$ & $16.29 \pm 0.19$ & $75.76 \pm 4.77$ \\
\hline D9 & $26.46 \pm 1.83$ & ND & $0.68 \pm 0.09$ & $27.15 \pm 2.52$ & $4.04 \pm 0.36$ & $58.33 \pm 1.17$ & $0.29 \pm 0.07$ & $1.19 \pm 0.11$ & $10.03 \pm 0.51$ & $5.13 \pm 0.24$ & $16.64 \pm 0.42$ & $74.97 \pm 3.93$ \\
\hline D10 & $29.23 \pm 1.19$ & ND & $0.70 \pm 0.15$ & $26.37 \pm 3.48$ & $3.89 \pm 0.45$ & $60.20 \pm 1.51$ & $0.17 \pm 0.04$ & $0.78 \pm 0.09$ & $10.94 \pm 0.95$ & $4.51 \pm 0.27$ & $16.40 \pm 0.42$ & $76.60 \pm 5.00$ \\
\hline D11 & $22.94 \pm 2.09$ & ND & ND & $16.20 \pm 1.02$ & $2.67 \pm 0.20$ & $41.81 \pm 0.95$ & D & $0.75 \pm 0.00$ & $11.84 \pm 1.12$ & $3.78 \pm 0.57$ & $16.36 \pm 0.56$ & $57.17 \pm 2.46$ \\
\hline
\end{tabular}

PRO, progoitrin; GRA, glucoraphanin; GAL, glucoalyssin; GNA, gluconapin; GBN, glucobrassicanapin; 4-OHGBS, 4-hydroxyglucobrassicin; GBS, glucobrassicin; 4-OMGBS, 4-methoxyglucobrassicin; NGBS, neoglucobrassicin. ND; not detected. Gluconasturtiin was not detected during seedling stages.

Table 3. Composition and content $\left(\mu \mathrm{mol} \cdot \mathrm{g}^{-1} \mathrm{DW}\right)$ of desulfo-glucosinolates during growth stages $(0-15$ weeks $)$ of Brassica rapa L. ssp. Peckinensis.

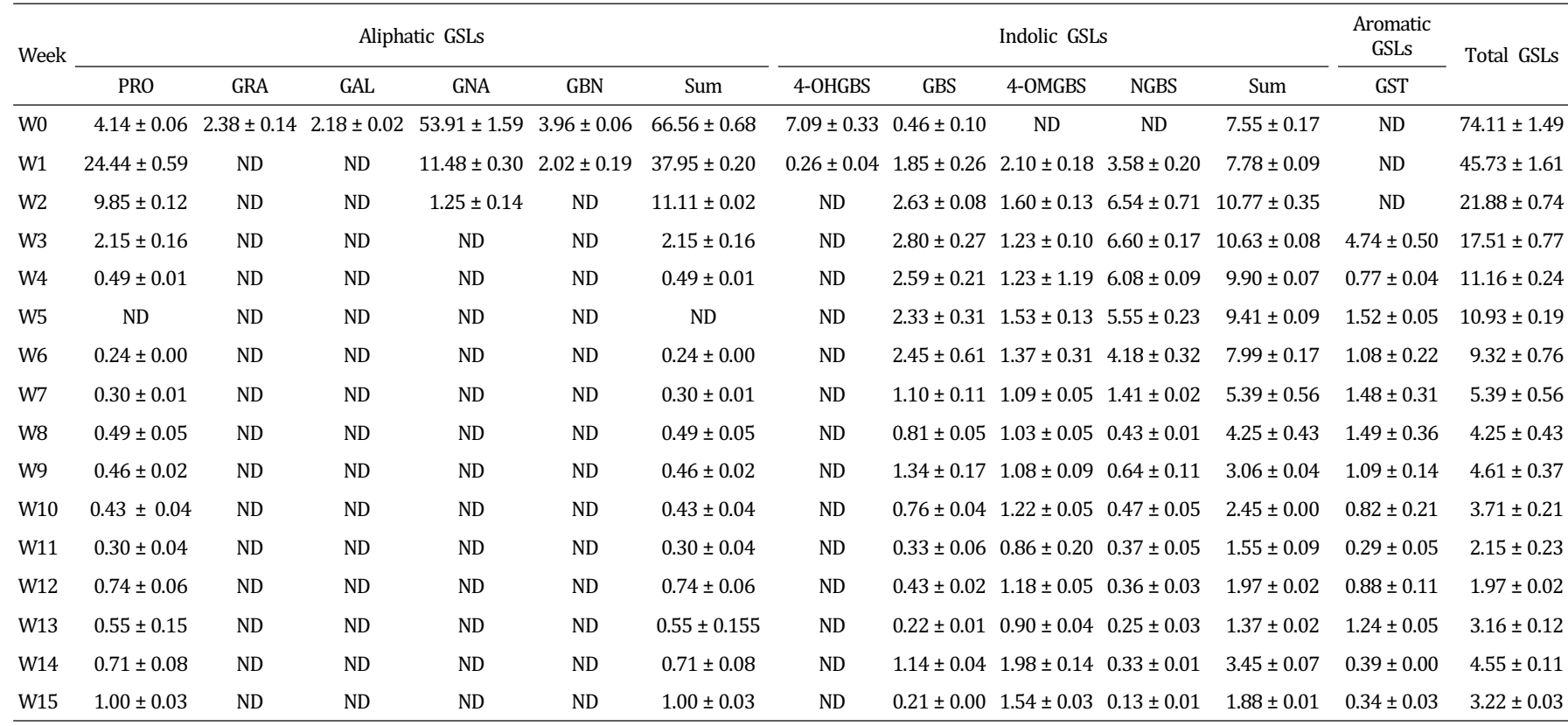

PRO, progoitrin; GRA, glucoraphanin; GAL, glucoalyssin; GNA, gluconapin; GBN, glucobrassicanapin; 4-OHGBS, 4-hydroxyglucobrassicin; GBS, glucobrassicin; 4-OMGBS, 4-methoxyglucobrassicin; NGBS, neoglucobrassicin; GST, gluconasturtiin. ND; not detected. 
of Korean Chinese cabbage.

Total GSL content in plant organs during seedling and growth stages of Korean Chinese cabbages ranged from 35.26 to $92.89 \mu \mathrm{mol} \cdot \mathrm{g}^{-1}$ DW (Table 2) and from 1.97 to $74.11 \mu \mathrm{mol} \cdot \mathrm{g}^{-1}$ DW (Table 3), respectively. The GSL content of vegetables varies considerably based on the date of planting, environmental conditions and length of growing seasons (Cartea et al., 2008). Previous work has shown that the total GSL content in five groups of Brassica oleracea (broccoli, Brussels sprouts, cabbage, cauliflower and kale) ranges from 10.9 to $25.1 \mu \mathrm{mol} \cdot \mathrm{g}^{-1} \mathrm{DW}$ (Kushad et al., 1999). From germination to seven days, the total GSL content was significantly greater than those of after eight days. Also, from eight days to 14 days, the total GSL concentration decreased gradually in sprouts tissues. In general, GSL content is high in young leaves (Bennet et al., 1995; Bergman, 1970; Brudenell et al., 1999) shoots and silique walls (Lein, 1972) and decrease as the tissue matures (Clossais-Besnard and Larher, 1991; Porter et al., 1991). Large and significant decrease also occurred between the contents in one and seven week growth stages, whereas changes in total GSLs levels were not shown significant difference after eight weeks stages. The decrease in GSL content during growth stages has also been reported in other Brassica species (Clossais-Besnard and Larher, 1991; McGrefor, 1998; Pereira et al., 2002); this phenomenon may be due to dilution of GSL content during tissue expansion (Chen and Andreasson, 2001). Also, these results would agree with the results from Clossais-Besnard and Larher (1991) who indicated that GSLs, accumulated during the vegetative stage, were catabolized during the reproductive stage especially during flowering and then GSL accumulation occurred again at maturation. Rosa and Heaney (1996) also reported a large decrease of GSLs from seedling leaves to mature leaves of B. juncea, B. oleracea and B. napus. The total GSL content in developing tissues of Korean Chinese cabbage varies widely depending on duration of seedling and grown stages.

The content of the individual GSLs identified in the plant tissues at the seedling and growth stages monitored is presented in Figs. 1-2. The GSLs were classified into three groups according to their side chain: aliphatic GSLs (progoitrin, glucoraphanin, glucoalyssin, gluconapin, glucobrassicanapin), indolic GSLs (4-hydroxyglucobrassin, glucobrassicin, 4-methoxyglucobrassicin, neoglucobrassicin) and aromatic

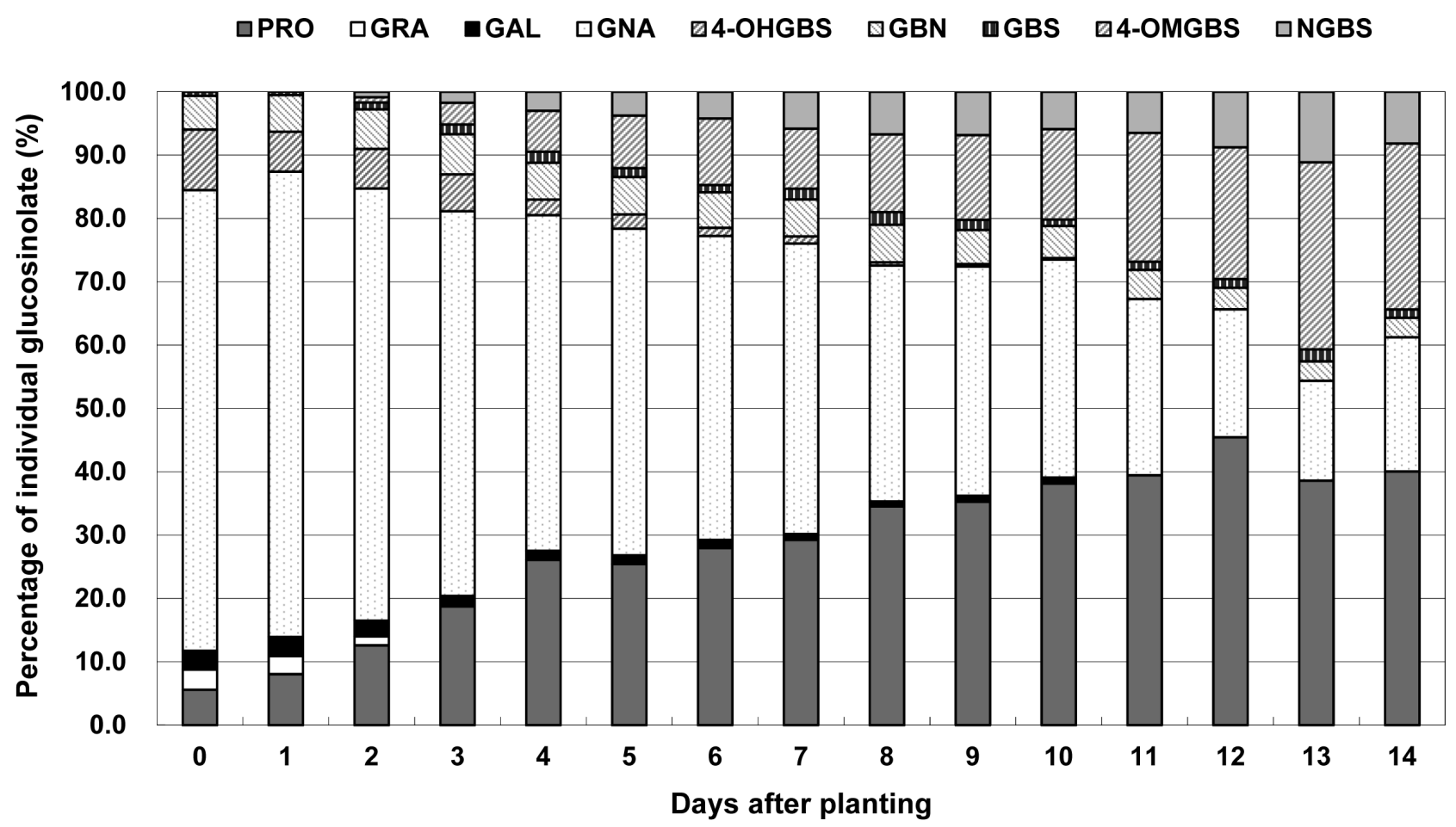

Fig. 1. Variation of individual glucosinolates proportion in Korean Chinese cabbage sprouts during seedling stages. PRO, progoitrin; GRA, glucoraphanin; GAL, glucoalyssin; GNA, gluconapin; GBN, glucobrassicanapin; 4-OHGBS, 4-hydroxyglucobrassicin; GBS, glucobrassicin; 4-OMGBS, 4-methoxyglucobrassicin; NGBS, neoglucobrassicin. Gluconasturtiin was not detected during seedling stages. 
GSL (gluconasturtiin).

The major GSLs in organs of the seedling (0-14 days) were gluconapin (15.7-73.4\%), progoitrin (5.59-45.4\%) and 4-methoxyglucobrassicin (0-29.5\%) with minor amount ( $\leq 10 \%$ of total GSLs) of glucoalyssin, glucobrassicanapin, glucobrassicin, neoglucobrassicin, 4-hydroxyglucobrassicin and glucoraphanin (Fig. 1). Aliphatic GSLs were predominant, with gluconapin as the most common GSL, followed by progoitrin during seedling of Korean Chinese cabbage. This result has been described previously for B. rapa (Bradshaw et al., 1984) with profile similar to that of B. napus (Sarwar and Kirkegaard, 1998). They were a major GSL group in seedling stage and remained as such during the growth monitored and their content decreased with seedling. Other study described that the content of aliphatic GSLs in leaves of $B$. oleracea and B. napus decreased sharply from seedling (14 days) to harvest (28 days) (Rose and Heaney, 1996). In agreement with the results recorded in our experiments. Especially, regarding the individual aliphatic GSLs, gluconapin content was highest in seed and germination period (about $73.1 \mu \mathrm{mol} \cdot \mathrm{g}^{-1} \mathrm{DW}$ ), and it declined gradually from 73 to $15 \%$ during seedling stages (0-14 days) in Korean Chinese cabbage. During the first seven days of imbibition of $B$. napus seeds, the content of the GSLs, mainly aliphatic type, decreases dramatically (Fieldsend and Milfor, 1994). However, change of progoitrin content (5.59-45.4\%) as the predominating aliphatic GSLs during seedling period showed opposite trends with other aliphatic GSLs in our study. For example, the evolution of gluconapin and progoitrin during seedling analyzed contrastive pattern, the former decreasing with the latter increasing in content throughout the sprouting period. Maybe the differences of change in individual aliphatic GSLs content between this study and previous reports are therefore due to different cultivars and growing conditions. In experiment, levels of 4-methoxyglucobrassicin were significantly higher between two days and 14 days than other indolic GSLs. Also, two indolic GSLs (4-methoxyglucobrassicin and neoglucobrassicin) increased considerably increasing seedling duration.

In the plant tissue during growth stages (1-15 weeks), neoglucobrassicin (7.83-54.4\%), progoitrin (0-53.4\%), 4methoxyglucobrassin (4.58-47.8\%), gluconasturtiin (6.95$35.1 \%)$ and glucobrassicin $(0.62-26.2 \%)$ were the main individual GSLs (Fig. 2). Four aliphatic GSLs (glucoraphanin, glucoalyssin, gluconapin, and glucobrassicanapin) and one indolic GSL (4-hydroxyglucobrassin) were detected as the

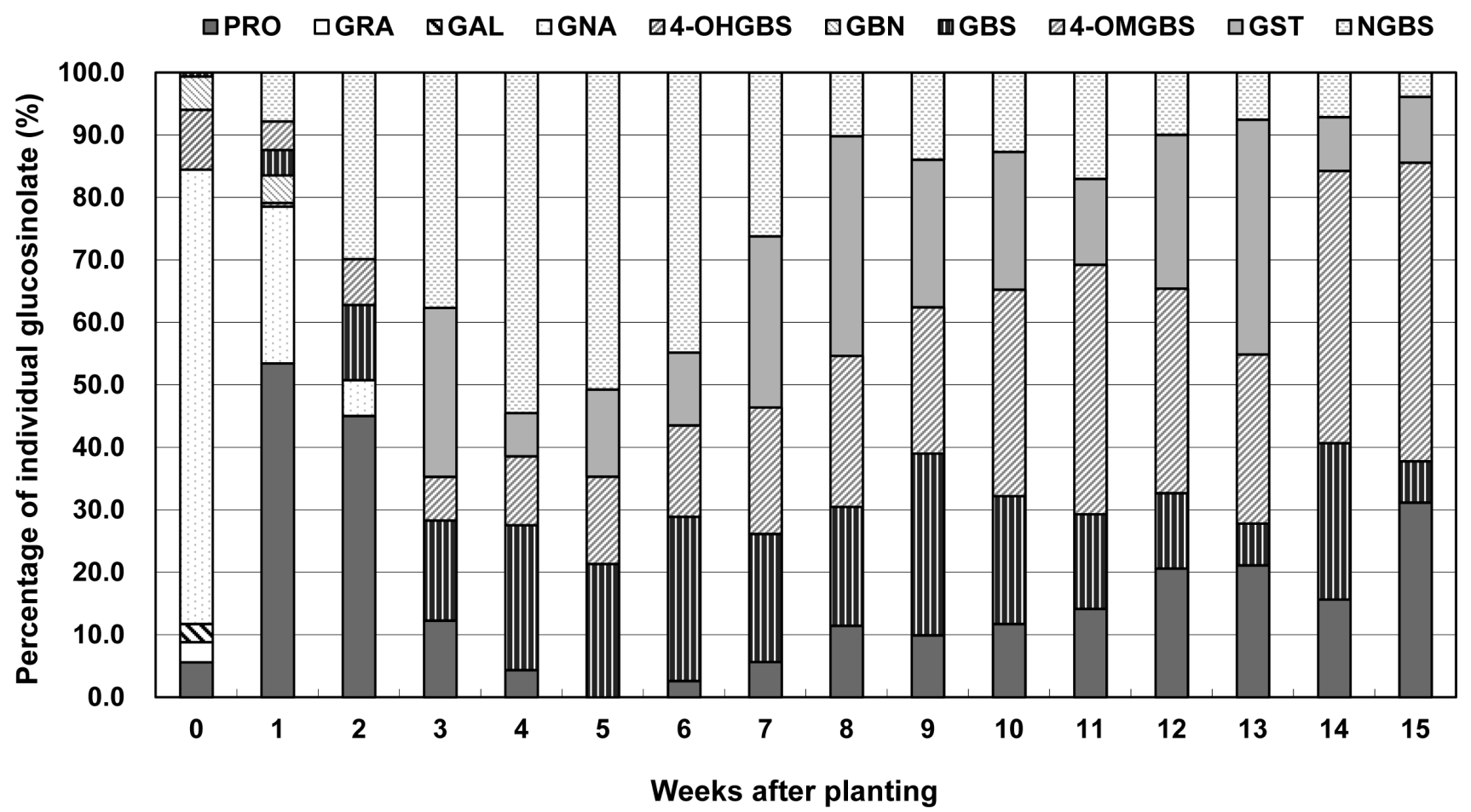

Fig. 2. Variation of individual glucosinolates proportion in tissues of Korean Chinese cabbage during growth stages. PRO, progoitrin; GRA, glucoraphanin; GAL, glucoalyssin; GNA, gluconapin; GBN, glucobrassicanapin; 4-OHGBS, 4-hydroxyglucobrassicin; GBS, glucobrassicin; 4-OMGBS, 4-methoxyglucobrassicin; NGBS, neoglucobrassicin; GST, gluconasturtiin. 
only important GSLs during germinating period (0-2 weeks). Individual and total GSLs in the leaves showed relatively rapid and complex changes throughout the growing period. The content of the major aliphatic GSLs, gluconapin and progoitrin tend to decrease sharply, on the other hand, the levels of indolic GSLs (4-methoxyglucobrassicin, glucobrassicin) and aromatic GSL (gluconasturtiin) were found to increase tend to at the beginning of growth stages. Especially, neoglucobrassicin had the highest content $\left(4.18-6.60 \mu \mathrm{mol} \cdot \mathrm{g}^{-1}\right.$ DW) between two and six weeks.

These results are in agreement with the decrease of total and individual GSLs conctent during the vegetative stage of rape reported by Clossais-Besnard and Larher (1991) and the observation of Paxman and Hill (1974) that leaves of kale contain higher amounts of thiocyanate ion (an hydrolysis product of both indol-3-ylmethyl-, 1methoxyindol-3-ylmethylglucosinolate). Other factors may include translocation of GSLs to other parts of the plant and the onset of senescence in order leaves which could also cause a disruption of cells and vacuoles and an activation of myrosinase leading to GSLs catabolism. In agreement with the results recorded in our experiment, mature tissues tend to have higher content of indol-3ylmethyl GSL than young tissues which have been related to de novo synthesis of this group of GSLs with growth (Kushad et al., 1999). GSLs are plant defence compounds and consistent with this function are accumulated preferentially in the organs that contribute most to plant fitness at a particular moment in the growth cycle (Grubb and able, 2006; Halkier and Gershenzon, 2006).

PCA is one of the most popular clustering methods form exploratory data analysis requiring no knowledge of data structures. Identification of compounds that exhibit the greatest variance within a population and determination of closely related compounds is possible using PCA. Ten major individual GSLs peak among seedling and growth stages were identified in the chromatogram by comparing the individual UV-visible spectra and their retention times that were used for PCA. The results are indicated by the principal components score plotting (Figs. 3 and 4). The abscissa represents the principal components 1 (PC1) score, while the ordinate represents the principle component 2 (PC2) score. Each plot in Fig. 3 implies the corresponding metabolome of nine GSL concentrations during seedling periods (0-14 days). PCA revealed that the two highest ranking principal components accounted for $90.0 \%$ of the total variance within the data. The component 1 , accounting for $68.5 \%$ of the total variance, showed the seedling stages according to the total GSLs content. Especially, the germination period (0-1day) clearly stood out from the other seedling stages in PC1, and four-day stage was different from the others in PC2. To investigate the contributors of the principal components further, the metabolic loadings in PC1 and PC2 were compared. In PC1, the corresponding loading was positive for 4-hydroxyglucobrassin (0.394), glucoalyssin (0.384), glucoraphanin $(0.354)$, gluconapin $(0.351)$ and glucobrassicanapin (0.206) and negative for 4-methoxyglucobrassicin $(-0.392)$, neoglucobrassicin $(-0.375)$, progoitrin $(-0.317)$ and glucobrassicin (-0.093). 4-Hydroxyglucobrassin
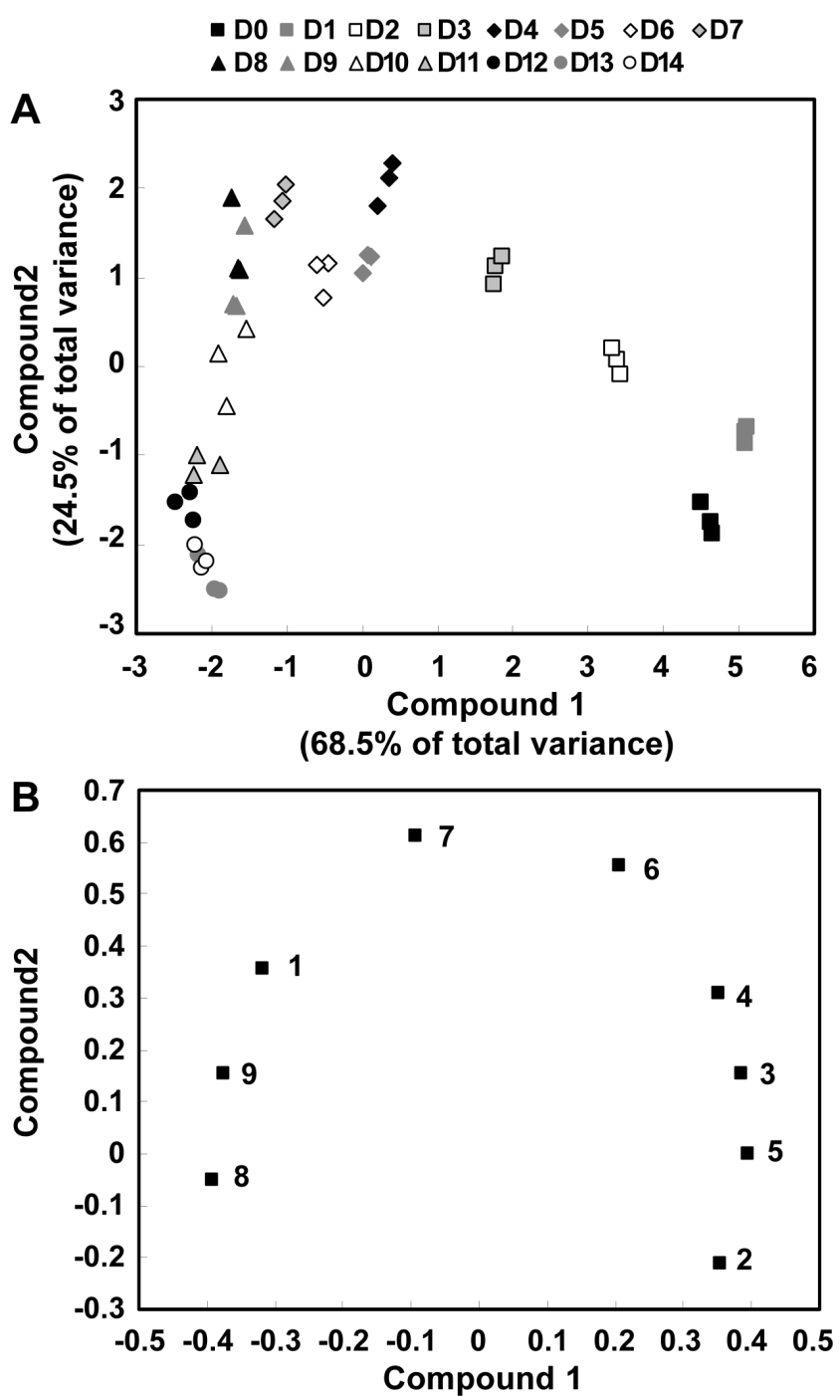

Fig. 3. Scores (A) and loading plots (B) of principal components 1 and 2 of the PCA results obtained from glucosinolates data on Korean Chinese cabbage during seedling stages from 0 day to 14 days. (1) Progoitrin; (2) Glucoraphanin; (3) Glucoalyssin; (4) Gluconapin; (5) 4-Hydroxyglucobrassin; (6) Glucobrassicanapin; (7) Glucobrassicin; (8) 4-Methoxyglucobrassicin; (9) Neoglucobrassicin. 
was the predominant individual GSLs in PC1. In PC2, the corresponding loading was positive for glucobrassicin (0.611), glucobrassicanapin (0.555), progoitrin (0.356), gluconapin (0.308), glucoalyssin $(0.155)$ and neoglucobrassicin $(0.155)$ and negative for glucoraphanin (-0.210), 4-methoxyglucobrassicin $(-0.050)$ and 4-hydroxyglucobrassin $(-0.000)$. PC2 directly correlated with glucobrassicin and was inversely related with glucoraphanin. Also, corresponding metabolome of ten GSLs levels during growth stages (0-15 weeks) showed scores and loading plots of PC 1 and PC2, respectively. In Fig. 4, PC1 and PC2 explained $55.3 \%$ and $21.5 \%$ of the total variance, respectively. PC1 was highly contributed
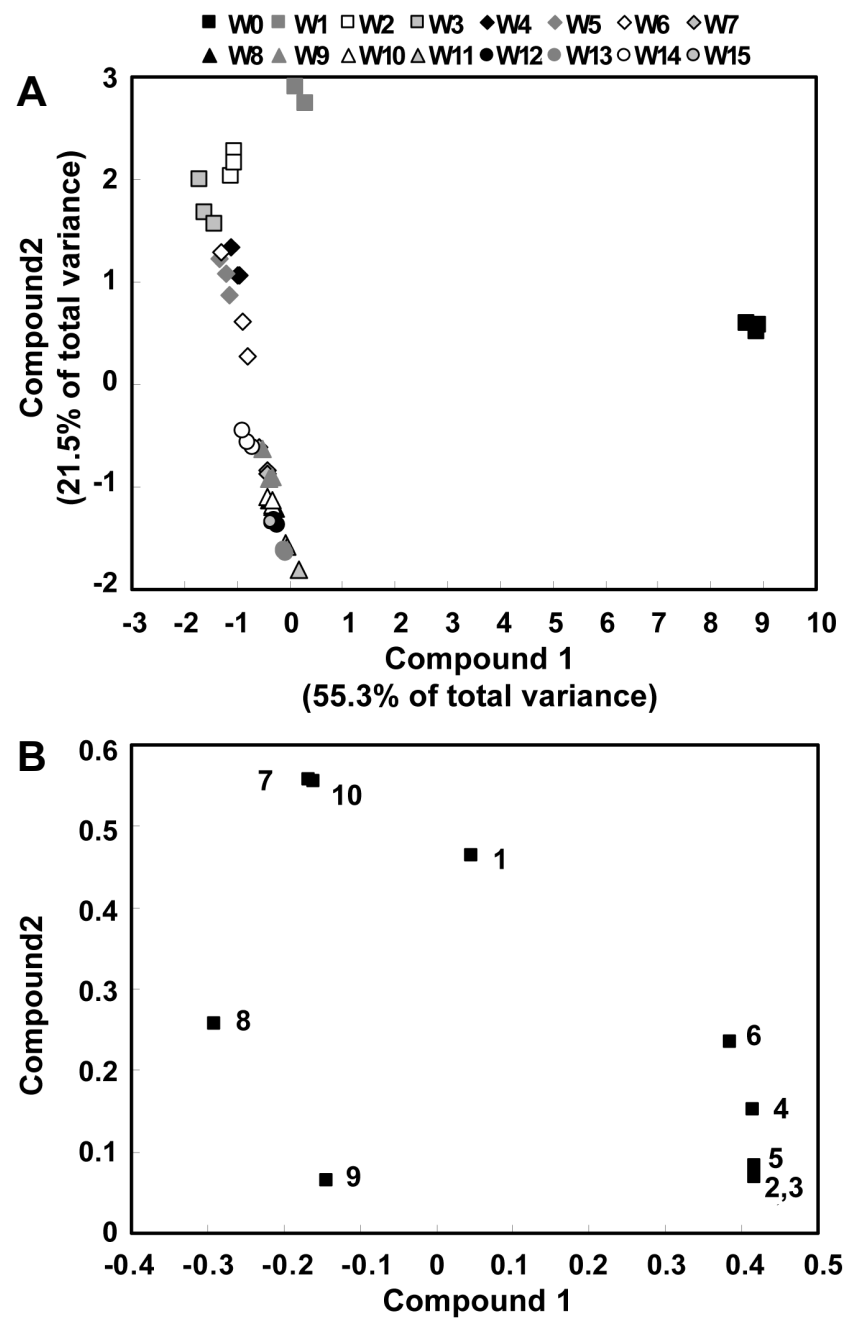

Fig. 4. Scores (A) and loading plots (B) of principal components 1 and 2 of the PCA results obtained from glucosinolates data on Korean Chinese cabbage during growth stages from 0 week to 15 weeks. (1) Progoitrin; (2) Glucoraphanin; (3) Glucoalyssin; (4) Gluconapin; (5) 4-Hydroxyglucobrassin; (6) Glucobrassicanapin; (7) Glucobrassicin; (8) 4-Methoxyglucobrassicin; (9) Gluconasturtiin; (10) Neoglucobrassicin. by glucolyssin (0.416), 4-hydroxyglucobrassin (0.416), glucoraphanin (0.415), glucobrassicanapin (0.384) and, but inversely correlated, by 4-methoxyglucobrassicin $(-0.290)$, glucobrassicin $(-0.166)$, neoglucobrassicin $(-0.160)$; PC2 was directly correlate with glucobrassicin (0.557), neoglucobrassicin (0.554), strictly inversely related with gluconasturtiin (0.064). These results analyzed give a good visual impression of the difference or similarity between growing stages. Total and individual GSL concentration of each seedling and growth stages can be grouped and PCA could fully distinguish between these growing Korean Chinese cabbage.

In conclusion, total GSL concentrations were significantly affected by seedling and growth stages and were higher in early developing period than in mature period of Korean Chinese cabbages. Also, our results showed significant difference of composition and proportion of individual GSLs according to plant growth stages.

\section{Literature Cited}

Barbieri, G., R. Pernica, A. Maggio, S.D. Pascale, and V. Fogliano. 2008. Glucosinolates profile of Brassica rapa L. Subsp. Sylvestris L. Janch. var. esculenta Hort. Food Chem. 107:1687-1691. Bennett, R.N., J. Ludwig-Muller, G. Kiddle, W. Hilgenberg, and R.M. Wallsgrove. 1995. Developmental regulation of aldoxime formation in seedlings and mature plants of Chinese cabbage (Brassica campestris ssp. pekinensis) and oilseed rape (Brassica napus): Glucosinolate and IAA biosynthetic enzymes. Planta. 196:239-244.

Bergman, F. 1970. The glucosinolate biosynthesis during the course of ontogenesis of Sinapis alba L. Z. Pflanzenphysiol. 62:362-375.

Brudenell, A.J.P., H. Griffiths, J.T. Rossiter, and D.A. Baker. 1999. The phloem mobility of glucosinolates. J. Exp. Bot. 50:745-756.

Bradshaw, J.E., R.K. Geaney, W.H. Macfarlane Smith, S. Gowers, D.J. Gemmell and G.R. Fenwick. 1984. The glucosinolate content of some fodder Brassicas. J. Sci. Food Agr. 35:977-981.

Cartea, M.E., P. Velasco, S. Obregón, G. Padilla, and A. De Haro. 2008. Seasonal variation in glucosinolate content in Brassica oleracea crops grown in northwestern Spain. Phytochemistry 69:403-410.

Charron, C.S., A.M. Saxton, and E.S. Carl. 2005. Relationship of climate and genotype to seasonal variation in the glucosinolatemyrosinase system I. Glucosinolate content in ten cultivars of Brassica oleracea grown in fall and spring seasons. J. Sci. Food Agr. 85:671-681.

Chew, F.S. 1988. Biological effects of glucosinolates, p. 155-181. In: H.G. Cutler (ed.). Biologically active natural products: Potential use in agriculture. American Chemical Society, Washington, D.C.

Chen, S. and E. Andreasson. 2001. Update on glucosinolate 
metabolism and transport. Plant Physiol. Bioch. 39:743-758.

Chu, Y.F., J. Sun, X. Wu, and R.H. Liu. 2002. Antioxidants and antiproliferative activities of common vegetables. J. Agr. Food Chem. 50:6910-6916.

Ciska, E., B. Martyniak-Przybyszewska, and H. Kozlowska. 2000. Content of glucosinolates in cruciferous vegetables grown at the same site for two years under different climatic conditions. J. Agr. Food Chem. 48:2862-2867.

Clossais-Besnard, N. and F. Larher. 1991. Physiological role of glucosinolates in Brassica napus. Concentration and distribution pattern of glucosinolates among plant organs during a complete life cycle. J. Sci. Food Agr. 56:25-38.

Cohen, J.H., A.R. Kristal, and J.L. Stanford. 2000. Fruit and vegetable intakes and prostate cancer risk. J. Natl. Cancer I. 92:61-68.

De March, G., D.I. McGregor, and G. Seguin-Shwartz. 1989. Glucosinolate content of maturing pods and seeds of high and low glucosinolate summer rape. Can. J. Plant Sci. 69:929-932.

Fahey, J.W., A.T. Zalcmann, and P. Talalay. 2001. The chemical diversity and distribution of glucosinolates and isothiocyanates among plants. Phytochemistry 56:5-51.

Fenwick, G.R., N.M. Griffiths, and R.K. Heaney. 1983a. Bitterness in Brussels sprouts (Brassica oleracea L. var. gemmifera): The role of glucosinolates and their breakdown products. J. Sci. Food Agric. 34:73-80

Fenwick, G.R., R.K. Heaney, and W.J. Mullin. 1983b. Glucosinolates and their breakdown products in food and food plants. CRC Cr. Rev. Food Sci. 18:123-201.

Fieldsend, J. and G.F.J. Milfor. 1994. Changes in glucosinolates during crop development in single- and double-low genotypes of winter oilseed rape (Brassica napus): I. Production and distribution in vegetative tissues and developing pods during development and potential role in the recycling of sulphur within the crop. Ann. Appl. Biol. 124:531-542.

Grubb, C.D. and S. Abel. 2006. Glucosinolates metabolism and its control. Trends. Plant. Sci. 11:89-100.

Halkier, B.A. and L. Du. 1997. The biosynthesis of glucosinolates. Trends. Plant Sci. 2:425-431.

Halkier, B.A. and J. Gershenzon. 2006. Biology and biochemistry of glucosinolates. Annu. Rev. Plant Biol. 57:303-333.

Jeffery, E.H., A.F. Brown, A.C. Kurilich, A.S. Keek, N. Matusheski, B.P. Klein, and J.A. Juvik. 2003. Variation in content of bioactive components in broccoli. J. Food Comp. Anal. 16:323-330.

Kushad, M.M., A.F. Brown, A.C. Kurilich, J.A. Juvik, B.P. Klein, M.A. Wallig, and E.H. Jeffery. 1999. Variation of glucosinolates in vegetable crops of Brassica oleracea. J. Agr. Food Chem. 47:1541-1548.

Lee, C.H. 1997. Lactic acid fermented foods and their benefits in Asia. Food Control. 8:259-269.
Lein, K.A. 1972. Genetical and physiological studies on the formation of glucosinolates in rape seeds: Localisation of the main site of glucosinolate biosynthesis by grafting experiments. Z Pflanzenphysiol 67:333-342.

Mattaus, B. and H. Luftmann. 2000. Glucosinolates in members of the family Brassicaceae: Separation and identification by LC/ESI-MS-MS. J. Agr. Food Chem. 48:2234-2239.

McGregor, D.I. 1998. Glucosinolate content of developing rapeseed (Brassica napus L "Midas") seedlings. Can. J. Plant Sci. 68:367-380.

Mithen, R.F., M. Dekker, R. Verkerk, S. Rabot, and T. Johnson lan. 2000. The nutritional significance, biosynthesis and bioavailability of glucosinolates in human foods (review). J. Sci. Food Agr. 80:967-984.

Paxman, P.J. and R. Hill. 1974. Thiocyanate content of Kale. J. Sci. Food Agr. 25:323-328.

Pereira, F.M.V., E. Rosa, J.W. Fahey, K.K. Stephenson, R. Carvalho, and A. Aires. 2002. Influence of temperature and ontogeny on the levels of glucosinolates in broccoli (Brassica oleracea Var. italica) sprouts and their effect on the induction of mammalian phase 2 enzymes. J. Agr. Food Chem. 50: 6239-6244.

Podsedek, A. 2007. Natural antioxidants and antioxidant capacity of Brassica vegetables: A review. LWT- Food Sci. Technol. 40:1-11.

Porter, A.J.R., A.M. Morton, G. Kiddle, K.J. Doughty, and R.M. Wallsgrove. 1991. Variation in the glucosinolate content of oilseed rape (Brassica napus L.), I. Effects of leaf age and position. Ann. Appl. Biol. 118:461-467.

Renwick, J.A.A. 2001. Variable diets and changing taste in plant insect relationships. J. Chem. Ecol. 27:1063-1076.

Rosa, E.A.S. and R. Heaney. 1996. Seasonal variation in protein, mineral and glucosinolate composition of Portuguese cabbages and kale. Anim. Feed Sci. Tech. 57:111-127.

Sarwar, M. and J.A. Kirkegaard. 1998. Biofumigation potential of Brassicas. II. Effect of environment and ontogeny of glucosinolate production and implications for screening. Plant Soil. 201:91-101.

Vallejo, F., F.A. Tomas-Barveran, and C. Carcia-Viguera. 2002. Potential bioactive compounds in health promotion from broccoli cultivars grown in Spain. J. Sci. Food Agr. 82:1293-1297.

Verhoeven, D.T., H. Verhagen, R.A. Goldbohm, P.A. van den Brandt, and G.A. van Poppel. 1997. A review of mechanisms underlying anti carcinogenecity by Brassica vegetables. Chem-Biol. Interact. 103:79-129.

West, L.G., K.A. Meyer, B.A. Balch, F.J. Rossi, M.R. Schultz, and G.W. Haas. 2004. Glucoraphanin and 4-hydroxyglucobrassicin contents in seeds of 59 cultivars of broccoli, raab, kohlrabi, radish, cauliflower, brussels sprouts, kale, and cabbage. J. Agr. Food Chem. 52:916-926. 